\title{
Correction to: Computational Fluid Dynamics Support for Fontan Planning in Minutes, Not Hours: The Next Step in Clinical Pre- Interventional Simulations
}

\author{
Petter Frieberg ${ }^{1} \cdot$ Nicolas Aristokleous $^{1,2} \cdot$ Pia Sjöberg $^{1} \cdot$ Johannes Töger $^{1} \cdot$ Petru Liuba $^{3} \cdot$ Marcus Carlsson $^{1,4}$
}

Published online: 1 February 2022

(c) Springer Science+Business Media, LLC, part of Springer Nature 2022

\section{Correction to: Journal of Cardiovascular Translational Research https://doi.org/10.1007/s12265-021-10198-6}

The Funding note that appeared in this article as originally published contained inaccurate information.

The original article has been corrected.

Publisher's Note Springer Nature remains neutral with regard to jurisdictional claims in published maps and institutional affiliations.

The online version of the original article can be found at https:// doi.org/10.1007/s12265-021-10198-6

Petter Frieberg

petter.frieberg@med.lu.se

1 Department of Clinical Sciences Lund, Clinical Physiology, Skåne University Hospital, Lund University, Lund, Sweden

2 Department of Mechanical \& Manufacturing Engineering, University of Cyprus, Nicosia, Cyprus

3 Department of Clinical Sciences Lund, Pediatric Heart Center, Skåne University Hospital, Lund University, Lund, Sweden

4 Laboratory of Clinical Physiology, NHLBI, National Institutes of Health, Bethesda, MD, USA 